11 - ORIGINAL ARTICLE

TECHNICAL SKILL

\title{
Is previous experience in laparoscopic necessary to perform robotic radical prostatectomy? A comparative study with robotic and the classic open procedure in patients with prostate cancer ${ }^{1}$
}

\author{
Felipe Monnerat Lott ${ }^{\mathrm{I}}$, Luciano Alves Favorito ${ }^{\mathrm{II}}$
}

DOI: http://dx.doi.org/10.1590/S0102-8650201500300000011

IFellow PhD degree, Postgraduate Program in Physiopathology and Surgical Sciences, Urogenital Research Unit, State University of Rio de Janeiro (UERJ), Rio de Janeiro-RJ, Brazil. Technical procedures, manuscript preparation.

IIAssociate Professor, Urogenital Research Unit, UERJ, Rio de Janeiro-RJ, Brazil. Design and supervised all phases of the study, manuscript writing, critical revision.

\section{ABSTRACT}

PURPOSE: To assess comparative results of robot-assisted radical laparoscopic prostatectomy (RARP) performed by surgeons without any experience in laparoscopic prostatectomy and the open procedure performed by surgeons with large experience.

METHODS: We analyzed 84 patients (50 subjected to robotic surgery) from June 2012 to September 2013. Data were prospectively collected in a customized database. Two surgeons carried out all the RARP cases. These two surgeons and six more performed the open cases. The perioperative outcomes between the two groups were analyzed with a minimum followup of 12 months.

RESULTS: The corporal mass index (BMI) was higher in the open group $(\mathrm{p}=0.001)$. There was more operatve time, less hospitalization and blood loss, better trifecta and pentafecta and earlier continence $(\mathrm{p}=0.045)$ in the robotic group $(\mathrm{p}=0.001)$. There was no difference in positive surgical margins but with greater extraprostatic extension in the open group $(\mathrm{p}=0.002)$.

CONCLUSIONS: Robot-assisted radical prostatectomy is a safe procedure even in the hands of surgeons with no previous experience. Besides this, better operative outcomes can be reached with this modern approach.

Key words: Prostate Neoplasms. Robotics. Prostatectomy. Urinary Incontinence. Sexual Dysfunction, Physiological. 


\section{Introduction}

Prostate cancer is the most common tumor after nonmelanoma cutaneos malignancy ${ }^{1}$. Surgery is one of the main treatments for the initial stages of adenocarcinoma of the prostate and the roboticassisted radical prostatectomy (RARP) is the most frequent method used. In 2012 in the United Kingdom, 29\% of radical prostatectomies were done with the da Vinci Surgical System (Intuitive Surgical Inc., Sunnyvale, $\mathrm{Ca})^{2}$, considered to be the most significant advance in minimally invasive surgery of this decade. In the USA the robotic procedure reached $53 \%$ of all surgical cases in $2008^{3}$.

One of the great merits of the advent of radical prostatectomy by laparoscopy and robotics is the better visualization of the structures during surgery, in contrast to open surgery, especially the ability to confirm the structure of the prostatic fascia. This enables the surgeon to select the best layer among the inter-fascial, intra-fascial or extra-fascial when a nervesparing procedure is carried out $t^{4-6}$.

Robotic surgery is still more expensive (on average 1.595 euros more expensive than the pure laparoscopic technique, which in turn is more costly than the traditional open procedure? LARP has a long learning curve, and hospitals where fewer than 80 robotic procedures are carried out per year have more complications compared with open surgery ${ }^{8}$. Some meta-analysis studies are controversial, but seem to show a tendency for superiority of robot-assisted radical prostatectomy (RARP) over pure laparoscopy or the open procedure when done by experts ${ }^{9}$.

The need for previous laparoscopic experience in radical prostatectomy is not universally acknowledged, but studies showing no need for laparoscopic skills previous to robotic surgery are rare ${ }^{10}$

The objective of this paper is to assess comparative results of robot-assisted radical prostatectomy done by surgeons without any experience in laparoscopic prostatectomy and the open procedure performed by surgeons with more than 10 years (19 years on average) of experience in this specific surgery.

\section{Methods}

This study was carried out in accordance with the ethical standards of the hospital's institutional committee on human experimentation.

We studied 84 patients with prostate cancer submitted to surgery during the period from June 2012 through September 2013. We divided the patients into two groups: Group 1 (50 patients) submitted to robot-assisted radical prostatectomy using the da Vinci Si surgical system (Intuitive Surgical Inc., Sunyvale, CA), excluding the first ten cases that were done with the proctor's assistance and Group 2 (34 patients) - submitted to open radical prostatectomy. Two surgeons with no previous experience in laparoscopic prostatectomy but with over 10 years of experience in the open procedure performed all the RARP procedures. The open cases were performed by the two surgeons with robotic experience plus four other surgeons having average experience of 25 years in radical prostatectomy.

The data were collected prospectively in a customized database. We analyzed the clinical aspects and the perioperative outcomes between the two groups with a minimum followup of 12 months. The primary endpoint was the comparative funcional oucome and the secondary endpoint was postoperative histological analysis. We compared the corporeal mass index, PSA, D'amico prostate cancer risk stratification, cancer stage, the Gleason score, days of hspitalization, blood loss, operative time, surgical margin, urinary continence and erectile dysfunction respecting the schedule decided in the Pasadena consensus ${ }^{11}$ and surgical complications in both groups.

Continence and potency were analyzed using the EPIC and sexual health inventory in men questionnaires (SHIM) (the five first questions of the International Inventory for Erectile Function - IIEF) and the erection hardness score ${ }^{12-14}$.

The patient was considered continent if no pads were used anymore. The patient was considered potent if intercourse was successful (erection hardness score 3 or 4 ) even with oral drugs but not with intracavernous injection.

Means were statistically compared using the MannWhitney test for all categorical variables and the Wilcoxon rank sum test for continuous variables. All tests were two-sided and $\mathrm{p}<0.05$ was considered statistically significant.

\section{Results}

The patients of the robotic group ranged in ages between 41 and 69 years old (mean=60.38) and had PSA values varying from 1 to $20.7 \mathrm{ng} / \mathrm{dL}$ (mean=8.27). The patients in the open surgery group had ages between 52 and 69 years old (mean=60.58) and had PSA values from 3.9 to $22 \mathrm{ng} / \mathrm{dL}$ (mean=7.53). There was no difference in age or PSA values between the two groups $(p=0.36$ and $\mathrm{p}=0.551$ respectively).

The Table 1 reports the age, PSA value, corporeal mass index, PSA, D'amico prostate cancer risk stratification, cancer stage, Gleason score, days of hospitalization, blood loss, operative time, surgical margin, urinary continence and erectile dysfunction respecting the schedule decided in the Pasadena consensus and surgical complications in both groups. The table also shows the statistical significance levels (p-values). 
TABLE 1 - The table shows the comparison between the parameters studied in group 1 (robotic) and group 2 (open prostatectomy) and the results of statistic analysis. $\mathrm{IQR}=$ interquartile range, $\mathrm{PSA}=$ prostate-specific antigen, $\mathrm{d}=\mathrm{days}, \mathrm{m}=$ months, $\mathrm{PO}=$ post-operative period.

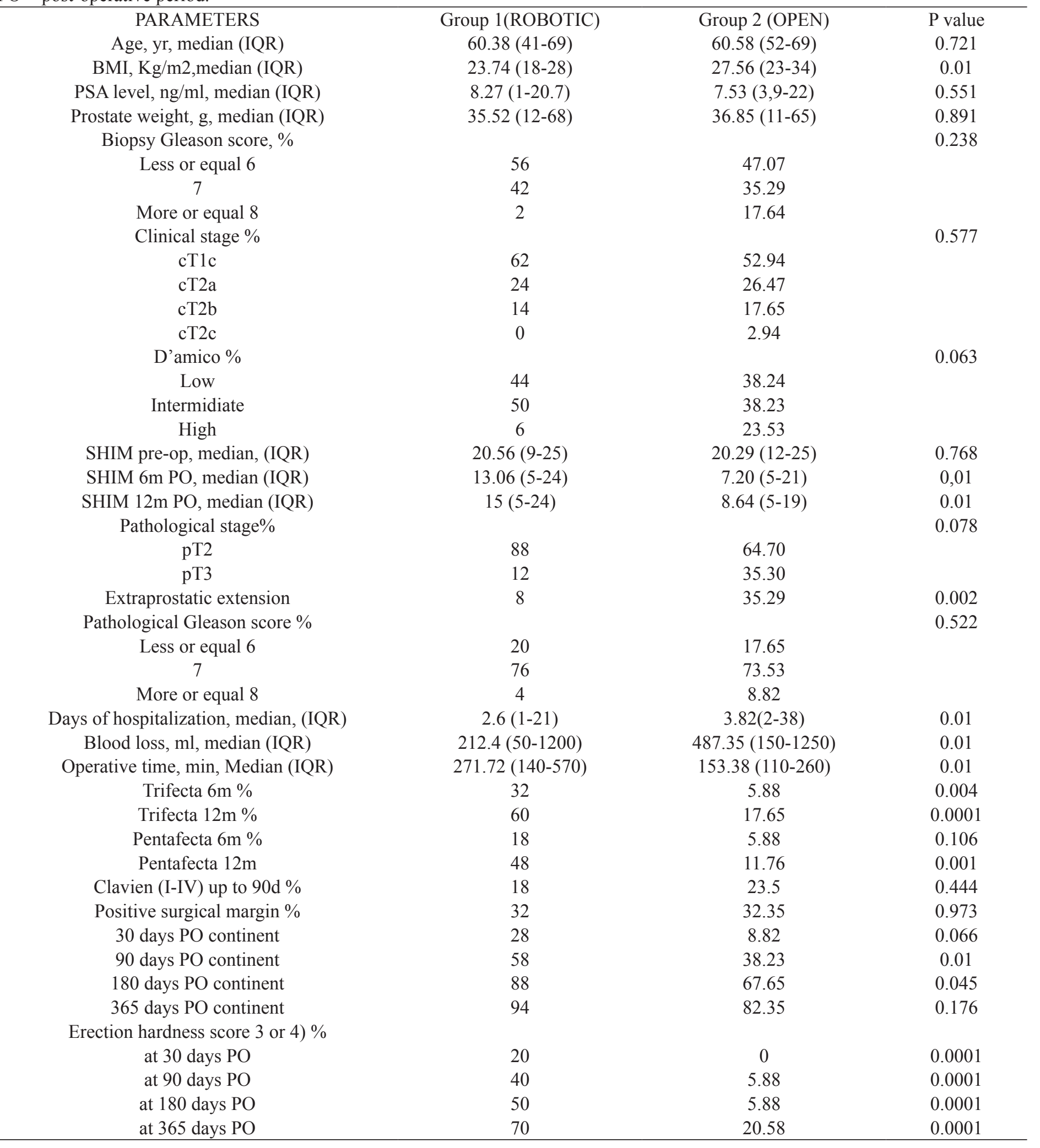

The corporal mass index was higher in the open group $(p=0.001)$. There were longer operatve time, shorter hospitalization and blood loss in the robotic group $(\mathrm{p}=0.001)$. Earlier continence was obtained in the robotic group $(\mathrm{p}=0.045)$ and the prostate weight and age, which are known factors that can affect these parameters, were similar in both groups. There was no difference in positive 
surgical margins but with greater extraprostatic extension (EPE) in the open group $(\mathrm{p}=0.002)$, although with similar pathological findings regarding the Gleason score $(\mathrm{p}=0.522)$ and pathological stage $(p=0.778)$. Trifecta and pentafecta at 12 months were better in the robotic group $(\mathrm{p}=0.001)$, but there was no difference in complications $(\mathrm{p}=0.444)$ or retreatment rates $(0.339)$.

\section{Discussion}

The development of radical retropupic prostatectomy (RRP) with nerve preservation has led to better preservation of potency and urinary continence ${ }^{15-17}$, causing RRP to quickly become the gold standard ORP for treatment of prostate cancer. The long learning curve for radical laparoscopic prostatectomy (RLP) and drawbacks such as the reduced amplitude of movement and the two-dimensional vision have hindered the diffusion of this technique among urologists ${ }^{18,19}$.

With the introduction of robotic surgery, these technical difficulties in laparoscopic surgery were lessened, due to, among other factors, the three-dimensional field of vision, hand-tremor filtration and greater ergonomic freedom of movement of the surgeon. The first robot-assisted radical prostatectomy (RARP) was carried out in Germany in 2000, and since then its popularity has grown with consequent reduction of conventional open radical prostatectomy $(\mathrm{ORP})^{20}$. Among the surgical treatment options for localized prostate cancer, RARP is currently the most often employed in the United States and Europe. At our institution, this procedure has been performed since July 2012, with encouraging results.

$\mathrm{Liu}^{21}$ evaluated the perioperatory results of 5.319 radical prostatectomies: 4.036 robot-assisted and 1.283 open. Although the operatory time was significantly longer in the RARP group, explained by the longer total time spent by the patient in operating room, there was a significantly lower number blood transfusions in the perioperatory period $(21 \%$ vs. $1.3 \%, \mathrm{p}<0.0001)$ and a shorter average hospitalization time (1.8 vs. 3.2 days). Postoperatory complications and death were 5\% in the RARP and $9 \%$ in the open group ( $\mathrm{p}<0.001$ ). In our study, we observed that all the mentioned indices were better in the robot-assisted group.

Interpretation of the index of complications is limited by the disparities between the various protocols adopted. In a previous study, $\mathrm{Hu}^{22}$ evaluated and compared the rate of complications of the two approaches between 2003 and 2005. The perioperatory complication rate was lower in the RARP than in the ORP (odds ratio $=0.73$, confidence interval 95\%, 0.60-0.90). Similarly, Trinh $^{23}$ demonstrated that patients submitted to RARP were less likely to present intraoperatory complications $(\mathrm{OR}=0.47, \mathrm{CI}$
$95 \%, 031-0.71)$ or postoperatory complications (OR $=0.86$, IC 95\%, 0.77-0.96 ). Our results show the same pattern, with similar complication rates.

A series to studies have demonstrated less bleeding in RARP compared to ORP. A wide-ranging literature review estimated that blood loss varies from 142-230 mL against 790-820 $\mathrm{mL}$ between robotic and traditional open surgery, respectively ${ }^{23}$. Likewise, a comparative study conducted by Rocco ${ }^{24}$ noted significant differences in the average bleeding, favoring RARP (200 vs. $800 \mathrm{~mL}$; p $<0.01$ ). Despite these findings, Farnham ${ }^{25}$ did not find any significant difference in the need for transfusion after RARP $(0.5 \%)$ and ORP $(2.9 \%, \mathrm{p}<0.14)$, which also occurred in our study. Nevertheless, recent studies ${ }^{22,23}$ reveal that patients submitted to RARP are less likely to receive blood transfusion $(\mathrm{OR}=0.11$, CI 95\%, 0.06-0.17) and (OR 0.34, CI 95\%, 0.28$0.40)$, respectively. No patient in our robotic group needed a blood transfusion, and only one patient $(2.9 \%)$ in the open group did.

Rocco et al..$^{24}$ also showed a shorter hospital stays (TIH) after RARP, with an average of three days for RARP and six days for ORP. We found significantly shorter hospital time in the RARP group.

As broad literature review recently demonstrated that robot-assisted surgery in comparison with the open technique is associated with smaller positive surgical margins for pT2 tumors (relative risk of 0.63 , confidence interval of $95 \%, 0.49-0.81$, $\mathrm{p}<0.001)$ and better sexual function results during 12 months (relative risk of 1.60, confidence interval of 95\%, 1.33-1.93, $\mathrm{p}<0.001$ ), and less impairment of urinary function during 12 months (relative risk of 1.06 , confidence interval of $95 \%, 1.02$ $1.11, \mathrm{p}<0.01)^{26}$. We observed that recovery of continence and potency was significantly better in the robot-assisted group.

Multi-institutional and prospective studies comparing the initial 30 cases of robotic prostatectomy performed by fellowshiptrained robotic surgeons and by experienced open surgeons showed that there was were smaller positive margins (15\% vs. $34 \%, \mathrm{p}=0.008$ ). This was not statistically different after analyzing the second 30 cases $^{27}$.

A recent study comparing the results of a surgeon experienced in the robotic technique (with analysis of cases after the 70th operation) and a surgeon with experience in open surgery showed very similar average robotic operation time to our results (234 minutes) and with a positive surgical margin in $24 \%$ of the patients treated using the da Vinci system ${ }^{28}$.

The weak points of our study are the small sample and the statistically significant differences between the two groups with respect to the BMI and EPE, which could have impaired the continence rate in the patients submitted to open surgery and 
Is previous experience in laparoscopic necessary to perform robotic radical prostatectomy? A comparative study with robotic and the classic open procedure in patients with prostate cancer

indicated a higher relative incidence of surgical margin in the group submitted to robotic surgery. Another point is that the open cases were done by a fellow in Urologic Oncology that has already completed the training in Urology with an experient surgeon as first auxiliary in all surgeries. Some patients, in both groups, could not afford the costs of the oral drugs for erection.

When there was positive surgical margin, EPE was present $12 \%$ of the time in group 1 and $54 \%$ of the time in group 2 . Despite this, there was not difference in the need for adjuvant treatment in the two groups. $\mathrm{Ou}^{29}$ stated that the positive surgical margin rates decrease every group of 50 patients submitted to robot-assisted surgery.

\section{Conclusions}

Robot-assisted radical prostatectomy is a safe procedure even in the hands of surgeons with no previous experience. Besides this, better operative outcomes can be reached with this modern approach.

\section{References}

1. Jemal A, Siegel R, Xu J, Ward E. Cancer statistics, 2010. CA Cancer J Clin. 2010 Sep-Oct;60(5):277-300. doi: 10.3322/caac.20073.

2. United Kingdom National Health Service (England) reference costs for financial year 2011-2012. UK Department of Health Web site. http://www.dh.gov.uk/health/2012/11/2011-12-reference-costs/. Accessed January 2013.

3. Yu H-Y, Hevelone ND, Lipsitz SR, Kowalczyk KJ, Hu KC. Use, costs and comparative effectiveness of robotic assisted, laparoscopic and open urological surgery. J Urol. 2012 Apr;187(4):1392-8. doi: 10.1016/j.juro.2011.11.089.

4. Zorn KC, Gofrit ON, Orvieto MA, Mikhail AA, Zagaja GP, Shalav AL. Robotic-assisted laparoscopic prostatectomy: functional and pathological outcomes with interfascial nerve preservation. Eur Urol. 2007 Mar;51(3):755-62. PMID: 17084520.

5. Rassweiler J. Intrafascial nerve-sparing laparoscopic radical prostatectomy: do we really preserve relevant nerve-fibers? Eur Urol. 2006 Jun;49(6):955-7. PMID: 16647805.

6. Walz J, Burnett AL, Costello AJ, Eastham JA, Graefen M, Guillonneau B, Menon M, Montorsi F, Myers RP, Rocco B, Villers A. A critical analysis of the current knowledge of surgical anatomy related to optimization of cancer control and preservation of continence and erection in candidates for radical prostatectomy. Eur Urol. 2010 Feb;57(2):179-92. doi: 10.1016/j.eururo.2009.11.009.

7. Close A, Robertson C, Rushton S, Shirley M, Vale L, Ramsay C, Pickard R. Comparative cost-effectiveness of robot-assisted and standard laparoscopic prostatectomy for treatment of men with localized prostate cancer: a health technology assessment from the perspective of the UK National Health Service. Eur Urol. 2013 Sep;64(3):361-9. doi: 10.1016/j.eururo.2013.02.040.

8. Sammon JD, Karakiewicz PI, Sun M, Sukumar S, Ravi P, Ghani KR, Bianchi M, Peabody JO, Shariat SF, Perrotte P, Hu JC, Menon M, Trinh QD. Robot-assisted versus open radical prostatectomy: the differential effect of regionalization, procedure volume and operative approach. J Urol. 2013 Apr;189(4):1289-94. doi: 10.1016/j.juro.2012.10.028.
9. Novara G, Ficarra V, Mocelin S, Ahlering TE, Carrol PR, Graefen M, Guazzoni G, Menon M, Patel VR, Shariat SF, Tewari AK, Van Poppel H, Zattoni F, Montorsi F, Mottrie A, Rosen RC, Wilson TG. Systematic review and meta-analysis of studies reporting oncologic outcome after robot-assisted radical prostatectomy. Eur Urol. 2012 Sep;62(3):382-404. doi: 10.1016/j.eururo.2012.05.047.

10. Leroy TJ, Thiel DD, Duchene DA, Parker AS, Igel TC, Wehle MJ, Goetzl M, Thrasher JB. Safety and peri-operative outcomes during learning curve of robot-assisted laparoscopic prostatectomy: a multiinstitutional study of fellowship-trained robotic surgeons versus experienced open radical prostatectomy surgeons incorporating robot-assisted laparoscopic prostatectomy. J Endourol. 2010 Oct;24(10):1665-9. doi: 10.1089/end.2009.0657.

11. Montorsi F, Wilson TG, Rosen RC, Ahlering TE, Artibani W, Carroll PR, Costello A, Eastham JA, Ficarra V, Guazzoni G, Menon M, Novara G, Patel VR, Stolzenburg JU, Van der Poel H, Van Poppel $\mathrm{H}$, Mottrie A. Best practices in robot-assisted radical prostatectomy: recommendations of the Pasadena Consensus Panel. Eur Urol. 2012 Sep;62(3):368-81. doi: 10.1016/j.eururo.2012.05.057.

12. Montague DK, Jarow JP, Broderick GA, Dmochowski RR, Heaton JP, Lue TF, Milbank AJ, Nehra A, Sharlip ID. Erectile dysfunction guideline update panel. J Urol. 2005 Jul;174(1):230-9. PMID: 15947645.

13. Rosen RC, Riley A, Wagner G, Osterloh IH, Kirkpatrick J, Mishra A. The International index of erectile function (IIEF): a multidimensional scale for assessment of erectile dysfunction. Urology. 1997 Jun;49(6):822-30. PMID: 9187685.

14. Ellison JS, He C, Wood DP. Stratification of post-prostatectomy urinary function using the Expanded Prostate Cancer Index Composite (EPIC). Urology. 2013 Jan;81(1):56-60. doi: 10.1016/j. urology.2012.09.016.

15. Reiner WG, Walsh PC. An anatomical approach to the surgical management of the dorsal vein and Santorini's plexus during radical retropubic surgery. J Urol. 1979 Feb;121(2):198-200. PMID: 423333.

16. Walsh PC, Donker PJ. Impotence following radical prostatectomy: insight into etiology and prevention. J Urol. 1982 Sep;128(3):492-7. PMID: 7120554.

17. Lepor H, Walsh PC. Long-term results of radical prostatectomy in clinically localized prostate cancer: experience at the Johns Hopkins Hospital. NCI Monogr. 1988;(7):117-22. PMID: 3173497.

18. Yates DR, Vaessen C, Roupret M. From Leonardo to da Vinci: the history of robot-assisted surgery in urology. BJU Int. 2011 Dec;108(11):1708-13. doi: 10.1111/j.1464-410X.2011.10576.x.

19. Ficarra V, Novara G, Artibani W, Cestari A, Galfano A, Graefen M, Guazzoni G, Guillonneau B, Menon M, Montorsi F, Patel V, Rassweiler J, Van Poppel H. Retropubic, laparoscopic, and robotassisted radical prostatectomy: a systematic review and cumulative analysis of comparative studies. Eur Urol. 2009 May;55(5):103763. doi: 10.1016/j.eururo.2009.01.036.

20. Finkelstein J, Eckersberger E, Sadri H, Taneja SS, Lepor H, Djavan B. Open versus laparoscopic versus robot-assisted laparoscopic prostatectomy: the European and US experience. Rev Urol. 2010 Winter;12(1):35-43. PMID: 20428292.

21. Liu JJ, Maxwell BG, Panousis P, Chung BI. Perioperative outcomes for laparoscopic and robotic compared with open prostatectomy using the National Surgical Quality Improvement Program (NSQIP) database. Urology. 2013 Sep;82(3):579-83. doi: 10.1016/j. urology.2013.03.080.

22. Hu JC, Wang Q, Pashos CL, Lipsitz SR, Keating NL. Utilization and outcomes of minimally invasive radical prostatectomy. J Clin Oncol. 2008 May;26(14):2278-84. doi: 10.1200/JCO.2007.13.4528.

23. Trinh QD, Sammon J, Sun M, Ravi P, Ghani KR, Bianchi M, Jeong W, Shariat SF, Hansen J, Schmitges J, Jeldres C, Rogers CG, Peabody JO, Montorsi F, Menon M, Karakjewicz PI. Perioperative outcomes 
of robot-assisted radical prostatectomy compared with open radical prostatectomy: results from the nationwide inpatient sample. Eur Urol. 2012 Apr;61(4):679-85. doi: 10.1016/j.eururo.2011.12.027.

24. Rocco B, Matei DV, Melegari S, Ospina JC, Mazzoleni F, Errico G, Mastropasqua M, Santoro L, Detti S, de Cobelli O. Robotic vs open prostatectomy in a laparoscopically naive centre: a matchedpair analysis. BJU Int. 2009 Oct;104(7):991-5. doi: 10.1111/j.1464410X.2009.08532.x.

25. Farnham SB, Webster TM, Herrell SD, Smith JA Jr. Intraoperative blood loss and transfusion requirements for robotic-assisted radical prostatectomy versus radical retropubic prostatectomy. Urology. 2006 Feb;67(2):360-3. PMID: 16461085.

26. Hu JC, Gu X, Lipsitz SR, Barry MJ, D'Amico AV, Weinberg AC, Keating NL. Comparative effectiveness of minimally invasive vs open radical prostatectomy. JAMA. 2009 Oct;302(14):1557-64. doi: 10.1001/jama.2009.1451.

27. Leroy TJ, Thiel DD, Duchene DA, Parker AS, Igel TC, Wehle MJ, Goetzl M, Thrasher JB. Safety and peri-operative outcomes during learning curve of robot-assisted laparoscopic prostatectomy: a multiinstitutional study of fellowship-trained robotic surgeons versus experienced open radical prostatectomy surgeons incorporating robot-assisted laparoscopic prostatectomy. J Endourol. 2010 Oct;24(10):1665-9. doi: 10.1089/end.2009.0657.

28. Gagnon LO, Goldenberg SL, Lynch K, Hurtado A, Gleave ME. Comparison of open and robotic-assisted prostatectomy: the University of British Columbia experience. Can Urol Assoc J. 2014 Mar;8(3-4):92-7. doi: 10.5489/cuaj.1707.

29. Ou YC, Yang CK, Chang KS, Wang J, Hung SW, Tung MC, Tewari AK, Patel VR. The surgical learning curve for robotic-assisted laparoscopic radical prostatectomy: experience of a single surgeon with 500 cases in Taiwan, China. Asian J Androl. 2014 SepOct;16(5):728-34. doi: 10.4103/1008-682X.128515.

\section{Acknowledgement}

To doctor Franz Santos Campos, head of Urology Department, Brazilian National Cancer Institute that authorized this study.

\section{Correspondence:}

Luciano Alves Favorito

Rua Professor Gabizo, 104/201

20271-320 Rio de Janeiro - RJ Brasil

Tel.: (55 21)2264-4679

Fax: (55 21)3872-8802

lufavorito@yahoo.com.br

Received: Nov 19, 2014

Review: Jan 20, 2015

Accepted: Feb 18, 2015

Conflict of interest: none

Financial source: none

${ }^{1}$ Research performed at Urogenital Research Unit, State University of Rio de Janeiro (UERJ) and Department of Urology, National Institute of Cancer (INCA), Rio de Janeiro-RJ, Brazil. 